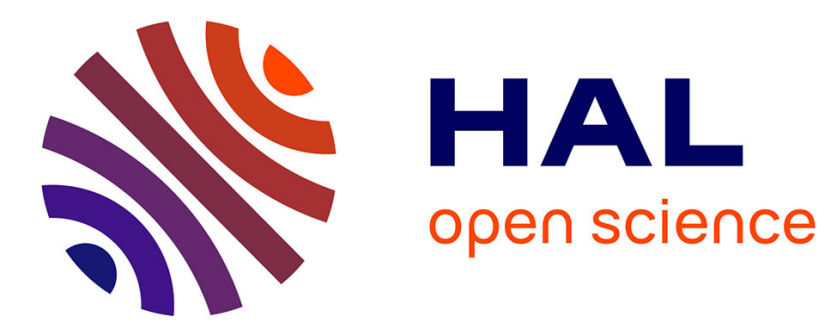

\title{
Object Kinetic Monte Carlo simulation of hydrogen clustering behaviour with vacancies in tungsten
}

Chao Meng, Lifang Wang, Ke Xu, Jiannan Hao, Hong-Bo Zhou, Xiaolin Shu, Shuo Jin, Linyun Liang, Guang-Hong Lu, Charlotte Becquart

\section{- To cite this version:}

Chao Meng, Lifang Wang, Ke Xu, Jiannan Hao, Hong-Bo Zhou, et al.. Object Kinetic Monte Carlo simulation of hydrogen clustering behaviour with vacancies in tungsten. Journal of Nuclear Materials, 2019, 526, pp.151768. 10.1016/j.jnucmat.2019.151768 . hal-02276642

HAL Id: hal-02276642

https://hal.univ-lille.fr/hal-02276642

Submitted on 3 Sep 2019

HAL is a multi-disciplinary open access archive for the deposit and dissemination of scientific research documents, whether they are published or not. The documents may come from teaching and research institutions in France or abroad, or from public or private research centers.
L'archive ouverte pluridisciplinaire HAL, est destinée au dépôt et à la diffusion de documents scientifiques de niveau recherche, publiés ou non, émanant des établissements d'enseignement et de recherche français ou étrangers, des laboratoires publics ou privés. 


\title{
Object Kinetic Monte Carlo simulation of hydrogen clustering behaviour with vacancies in tungsten
}

\author{
Chao Meng ${ }^{1,2}$, Lifang Wang ${ }^{3}$, Ke Xu ${ }^{1,2}$, Jiannan Hao ${ }^{1,2}$, Hong-bo Zhou ${ }^{1,2}$, Xiaolin Shu ${ }^{1,2}$, \\ Shuo Jin ${ }^{1,2}$, Linyun Liang ${ }^{2, *}$, Guang-Hong Lu ${ }^{1, *}$, C.S. Becquart ${ }^{4}$ \\ ${ }^{1}$ Department of Physics, Beihang University, Beijing, 100191, China \\ ${ }^{2}$ Beijing Key Laboratory of Advanced Nuclear Materials \& Physics, Beihang University, Beijing 100191, China \\ ${ }^{3}$ Institute of Applied Physics and Computational Mathematics, Beijing 100094, China \\ ${ }^{4}$ Univ.Lille, CNRS,INRA, ENSCL, UMR 8207,UMET, Unité Matériaux et Transformations, F 59000 Lille, France
}

\begin{abstract}
We apply the Object Kinetic Monte Carlo method to simulate the hydrogen $(\mathrm{H})$ clustering behaviour with large vacancy $(\mathrm{V})$ clusters in tungsten. The main advantage of this method is to consider the temperature effects, large V clusters, and long-time evolution. It is thus a very useful tool to study the microstructure evolution of defects in irradiated materials covering from atomic scale to mesoscale. Simulation results show that the number of trapped $\mathrm{H}$ atoms by $\mathrm{V}$ and $\mathrm{V}$ clusters decreases with the increase of temperature. This is expected, because the de-trapping ability of $\mathrm{H}$ atoms increases when the temperature is increased. With the correction of the zero-point-energy in calculating binding energies, the present results show that the number of $\mathrm{H}$ atoms trapped by monovacancy decreases for all studied temperatures. We also found that the trapping ability of $\mathrm{V}$ clusters for $\mathrm{H}$ decreases with the increase of the sizes of $\mathrm{V}$ clusters, independent on temperature. The $\mathrm{H}$ concentration can largely affect the clustering behaviour of $\mathrm{H}_{\mathrm{m}} \mathrm{V}_{\mathrm{n}}$. When the $\mathrm{H}$ saturation concentration is reached, the clustering behaviour of $\mathrm{H}_{\mathrm{m}} \mathrm{V}_{\mathrm{n}}$ is mainly determined by the sizes of $\mathrm{V}$ clusters.
\end{abstract}

Keywords: OKMC, hydrogen, vacancy clusters, tungsten

\footnotetext{
* Corresponding author: E-mail address: 1gh@buaa.edu.cn (G. H. Lu)

* Corresponding author: E-mail address: lyliang@buaa.edu.cn (L. Y. Liang)
} 


\section{Introduction}

Tungsten (W), because of its high melting point, thermal conductivity, and sputtering resistance, is one of the most promising candidates of plasma facing materials (PFM) for future fusion reactors such as International Thermonuclear Experimental Reactor (ITER) [1,2]. During the operation of the fusion reactor, W will be exposed to the low-energy $(<100 \mathrm{eV})$, high-flux $\left(>10^{24} / \mathrm{m}^{2} \mathrm{~s}\right)$ hydrogen $(\mathrm{H})$ and helium plasma irradiation, as well as a continuous bombardment of $14.1 \mathrm{MeV}$ neutrons escaped from nuclear fusion reactions [3]. The plasma irradiation on the PFM can lead to the accumulation of $\mathrm{H}$ atoms and their isotopes in it. The escaped high energy neutrons colliding with $\mathrm{W}$ lattice atoms can cause the displacement of atoms along their paths and create Frenkel pairs of self-interstitial atoms (SIAs) and vacancies in the materials. The continuous creation of vacancies or vacancy clusters $\left(V_{n}\right.$, where $n$ is the number of vacancies) in $\mathrm{W}$ under irradiation can serve as traps for $\mathrm{H}$ and its isotopes. This was experimentally confirmed by using the thermal desorption spectroscopy (TDS) $[4,5]$. High retention of $\mathrm{H}$ isotopes in $\mathrm{W}$ can significantly degrade the fueling efficiency of burning plasmas and thus bing the severe safety concern of reactors. Therefore, it is essential to understand and control the behaviour of $\mathrm{H}$ isotopes in irradiated $\mathrm{W}$ such as the clustering of $\mathrm{H}$ isotopes with vacancy defects.

Simulation approaches are effective tools that can be used to understand the properties of materials. Many researchers have already performed atomic simulations on the microscopic interaction mechanism of $\mathrm{H}$ with irradiated defects in W. By using the Density Functional Theory (DFT) method, Qin et al. [6] found that vacancies are very easily formed near the vicinity of $\mathrm{H}$ atoms. Liu et al. [7] studied the clustering of $\mathrm{H}$ to vacancies and pointed out that a monovacancy can provide a low-density region of electrons, which decreases the binding energy of $\mathrm{H}$ to $\mathrm{V}_{1}$ suggesting that $\mathrm{H}$ atoms can be easily trapped by $\mathrm{V}_{1}$. Results showed that a $\mathrm{V}_{1}$ can accommodate up to $10 \mathrm{H}$ atoms. Later on, by taking the zero-point energy (ZPE) into account in the calculation of binding energies, Sun et al. [8] showed that a $V_{1}$ can trap up to $12 \mathrm{H}$ atoms. Recently, Valles et al. [9] calculated the binding energies of $\mathrm{H}$ with both $\mathrm{V}_{1}$ and $\mathrm{V}$ clusters with a number of $\mathrm{V}$ up to 4 in order to study the effect of grain boundaries on the defect revolution and $\mathrm{H}$ retention in W. Besides the DFT method, the molecular statics (MS) based on empirical 
potentials is another way to study the clustering behaviour of atoms. Using the MS method, Wang et al. [10] systematically investigated the interaction of $\mathrm{H}$ with $\mathrm{V}$ clusters containing up to 10 vacancies $\left(\mathrm{V}_{10}\right)$ by using a newly developed embedded-atom method (EAM) potential. More recently, owing to the genetic algorithm (GA), they can further increase the number of vacancies up to $40\left(\mathrm{~V}_{40}\right)$ [11]. The energetically favorable diffusion path for a single $\mathrm{H}$ atom in bulk $\mathrm{W}$ is from a tetrahedral interstitial site (TIS) to another TIS. The diffusion barrier is $0.20 \mathrm{eV}$ [12]. It was shown in Ref. [7] that the diffusion barrier reduces when a $\mathrm{V}$ is present. For the case of a single $\mathrm{V}$ trapping multiple $\mathrm{H}$ atoms, the diffusion barrier for the first $6 \mathrm{H}$ atoms moving from the $1 \mathrm{NN}$ to the stable positions nearby is only $0.02 \mathrm{eV}$, and $0.18 \mathrm{eV}$ for the $7^{\text {th }} \mathrm{H}$ atom, which is lower than that in the bulk. However, atomic simulations are limited by the time and space scales and MS simulations are performed at temperature $0 \mathrm{~K}$. These simulations may not reflect the real clustering behaviour of $\mathrm{H}$ and large $\mathrm{V}$ clusters at large scale and high operation temperatures.

Object Kinetic Monte Carlo (OKMC) is a very important simulation method. It uses activation energies obtained at the atomistic scale to study the evolution of defects at large scale. Yang et al. $[13,14]$ studied the diffusion coefficients of $\mathrm{H}$ atom in both pure $\mathrm{W}$ and a reconstructed $\left(\begin{array}{lll}0 & 0 & 1\end{array}\right) \mathrm{W}$ surface using OKMC. A very good agreement between the OKMC results and experimental data was achieved. Oda et al. [15] studied the effect of a $V_{1}$ on the diffusion coefficient of $H$ in $W$. They successfully reproduced the experimental results of $\mathrm{H}$ diffusivity. G. Valles et al. [9] investigated the $\mathrm{H}$ retention in $\mathrm{W}$ with their own OKMC code. Castin et al. studied the microstructural evolution of $\mathrm{W}$ under low-dose neutron irradiation using the OKMC model [16]. Their results suggested that the size and density of voids as a function of irradiation dose and temperature were consistent with experimental observations [16]. In another study by Castin et al., they incorporated the effects of the transmutation element of Re and interstitials of $\mathrm{W}$ and $\mathrm{C}$ on the microstructural evolution in their OKMC model. The model gave a realistic prediction for the formation of nanovoids and TEM-visible SIA loops under neutron or highenergy ion irradiation conditions. The transmuted Re atoms also affect the dislocation loops greatly through a complicated transmutation-diffusion-segregation mechanism [17]. Meng et al. [18] studied 
the clustering behaviour of $\mathrm{H}$ with monovacancies using their own OKMC code, and the temperature dependence of dominating $\mathrm{H}_{\mathrm{m}} \mathrm{V}_{1}$ clusters was obtained. As shown above, although some work on the clustering of $\mathrm{H}$ with $\mathrm{V}$ has already been done, the temperature-dependent clustering behaviour of $\mathrm{H}$ and large $\mathrm{V}$ clusters for a long-time evolution in $\mathrm{W}$ remains unclear.

In this work, we systematically investigate the clustering behaviour of $\mathrm{H}$ with $\mathrm{V}$ clusters in $\mathrm{W}$ using the OKMC method and our own code, which has been previously validated by studying the behavior of $\mathrm{H}$ clustering with monovacancies [18]. We should mention that SIAs are not considered in the simulation although SIAs and vacancies are generated as Frankel pairs after a cascade during the irradiation. The reseaons can be explained in two aspects: firtly, the interaction of SIAs with $\mathrm{H}$ atoms can be neglected. C. S. Becquart et al. [19] showed that the calculated binding energy of SIA and H is $0.33 \mathrm{eV}$, which indicates that the interaction of SIA with $\mathrm{H}$ is relatively weak comparing with the $\mathrm{H}$ migration with an energy of $0.20 \mathrm{eV}$ especially at the temperature range used in our simulations. Thus, the interaction of $\mathrm{H}$ with SIA can be neglected. Secondly, for the interaction of SIAs with vacancy defects, it is believed that the presence of SIAs can affect the clustering behaviour of vacancies. However, in our simulation, we study a bulk case without the presence of any sinks. The SIAs can't be annihiliated in the entire simulation and their migration events will be always selected between cascades in the MC simulation due to its very low migration energy of $0.013 \mathrm{eV}$ [19]. These migration events of SIAs doesn't bring much useful information except significantly increasing the simulation time [17]. To avoid these time consuming migration events of SIAs, our simulation starts from the stage where fastmoving SIAs are assumed to be already annihilated by sinks after a cascade, and those sinks are not explicitly included in our simulation. Therefore, we studied a simple case in which we mainly focus on the clustering behaviours of $\mathrm{H}$ and vacancy defects in the bulk W. The effects of temperature, V size, and the initial $\mathrm{H}$ concentration on the clustering behaviour of a single $\mathrm{H}$ with $\mathrm{V}$ clusters in $\mathrm{W}$ were thoroughly investigated.

\section{Computational method}


In this section, we first present the algorithms of the OKMC simulation approach. Then the parameters in the OKMC model for describing the properties of $\mathrm{H}, \mathrm{V}$, and their clusters are detailed.

\subsection{The Object Kinetic Monte Carlo model}

In the OKMC model, various configurations of defects are represented by different states in the system and the transitions between these states follows the Transition State Theory (TST), that is, the transition rates of different states depend on the initial and final states, and are independent on the time. More precisely, in our approach (and many OKMC models), we use the Harmonic Transition State Theory, as a particular TST. The corresponding possibility of transition is assumed to follow an Arrhenius law with an activation energy $E_{a}$ and a pre-factor $P_{0}[20]$ expressed by

$$
P=P_{0} \times e^{-E_{a} / k_{B} T}
$$

where $k_{B}$ and $T$ is the Boltzmann constant and the absolute temperature, respectively. The time increment is acquired by the residence time algorithm (RTA) [21] known as

$$
\Delta t=\frac{-\ln (r)}{\sum P},
$$

where $r$ is a random number between 0 and 1.

The above OKMC model only considers the temporal evolution of events. For the spatial evolution of events, we define it using the following schemes. The defects are described as spherical objects characterized by their compositions, shapes, center-of-mass, reaction radii, diffusion barriers, and binding energies. The details of the diffusion processes of objects are ignored and their diffusion are treated as jump events to the desired lattice sites. Vacancies and $\mathrm{H}$ atoms in the bulk diffuse randomly between the nearest body-centered cubic (bcc) sites and TIS sites with equal rate, respectively. The detailed diffusion mechanism is based on the atomic simulation and will be explained in the next section. Once a $\mathrm{H}$ moves towards a V or V cluster and their distance is less than the sum of the radius of these two objects, they can combine together and form a $\mathrm{H}_{\mathrm{m}} \mathrm{V}_{\mathrm{n}}$ cluster. Meanwhile, a $\mathrm{H}$ atom has a certain 
probability to be emitted from the formed cluster and the emitted $\mathrm{H}$ is randomly put at an nearest TIS site which is more than twice the sum of the radius of the two objects.

In order to describe the clustering behaviour of $\mathrm{H}$ and $\mathrm{V}$, the $\mathrm{OKMC}$ model requires a complete parameter dataset of the $\mathrm{H}, \mathrm{V}$, and their clusters. These parameters include the pre-factor for migration probability, the migration energy (or diffusion barrier), the pre-factor for emission probability, the binding energy, and capture radius. These parameters are usually obtained from the atomic scale simulations or experimental results.

\subsection{Parameterisation of vacancy clusters}

The diffusion of $\mathrm{V}$ and $\mathrm{V}$ clusters is treated as they jump from one bcc lattice site to one of the eight $1^{\text {st }}$ Nearest Neighbor (1NN) bcc lattice sites with the migration energy of $1.66 \mathrm{eV}$ [22]. The binding energy of $\mathrm{V}$ to $\mathrm{V}_{1}, \mathrm{~V}_{2}$, and $\mathrm{V}_{3}$ cluster is taken as $0.01,0.19$, and $0.78 \mathrm{eV}$, respectively, as reported by Heinola et al. [23]. For large V clusters, Becquart et al. [19] proposed a capillary approximation to estimate their binding energies. As for migration, the pre-factor $P_{0}$ of the migration probability is considered to be a function of $\mathrm{V}$ cluster size, and a migration energy of $1.66 \mathrm{eV}$ is assumed for all $\mathrm{V}$ clusters. In the study of Castin et al. [16], the migration energies of various sizes V clusters were carefully studied. Results show that it is $2.77 \mathrm{eV}$ for $\mathrm{V}$ clusters up to a size of 250 . However, the $\mathrm{H}$ atom, with its migration energy of $0.20 \mathrm{eV}$, is quite similar to the case of SIA in Ref. [17], where SIA migration events are always selected by the MC algorithm due to its low migration energy, resulting in virtually frozen of vacancy defects. In this light, the V and V clusters are immobile in our simulation. The radius for a single $\mathrm{V}$ is $1.36 \AA$ [24], and the radii for $\mathrm{V}$ clusters are given by an empirical expression related to the sizes of $V_{n}$ clusters [19]. Impurities like carbon (C) atoms, are unavoidably present in W. As mentioned by Castin et al. [16], the technologically pure tungsten can have 200 appm or higher concentration of carbon. On the other hand, MD simulation results show that the H-C binding is very weak. The binding energies between $\mathrm{H}$ and $\mathrm{C}$ in the bulk $\mathrm{W}$ are in the range of 0.04-0.06 eV [25], which are far less than that of $\mathrm{H}$ with $\mathrm{V}$ around $1.20 \mathrm{eV}$ [9]. Moreover, simulation results show that the 
existence of $\mathrm{C}$ atom in $\mathrm{V}$ has a minor effect on the binding energies of $\mathrm{H}$ and $\mathrm{V}$, changing from $1.16 \mathrm{eV}$ to $1.19 \mathrm{eV}$ [25]. Therefore, the effect of carbon atoms on the trapping behaviors of $\mathrm{H}$ and $\mathrm{V}$ clusters can be ignored in this simulation.

\subsection{Parameterisation of hydrogen diffusion}

DFT calculations suggested that TIS is the energetically favourable site and the octahedral interstitial site (OIS) is the second energetically favourable site for $\mathrm{H}$ in $\mathrm{W}$ with a slightly difference of diffusion barrier of $0.29 \mathrm{eV}$ [8]. Thus, there are two possible diffusion paths, TIS-TIS with a diffusion barrier of $0.20 \mathrm{eV}$ and TIS-OIS-TIS with a diffusion barrier of $0.38 \mathrm{eV}$, for $\mathrm{H}$ in pure $\mathrm{W}$ [26]. However, Frauenfelder et al. [27] reported an experimental value of $0.39 \mathrm{eV}$ for the diffusion barrier of $\mathrm{H}$, which is higher than the DFT result [26]. Liu et al. calculated the diffusion coefficients of $\mathrm{H}$ in $\mathrm{W}$ at temperatures from $1900 \mathrm{~K}$ to $3000 \mathrm{~K}$ using molecular dynamics (MD) [28]. Their results showed that $\mathrm{H}$ atoms can be trapped by vacancies below $1900 \mathrm{~K}$. And above $1900 \mathrm{~K}$, V can still have a significant impact on $\mathrm{H}$ diffusion. Recently, Oda et al. [15] calculated the diffusion coefficients of $\mathrm{H}$ in $\mathrm{W}$ taking $\mathrm{V}$ into account by using an OKMC model with the diffusion barrier of $0.25 \mathrm{eV}$ as an input parameter. They suggested that the diffusion barrier of $0.25 \mathrm{eV}$ is a reasonable value and the higher experimental value of $0.39 \mathrm{eV}$ may be caused by an over-estimation of the trapping influence by $\mathrm{V}$. Considering the large effect of $\mathrm{V}$ on $\mathrm{H}$ diffusion, we use the diffusion barrier of $0.20 \mathrm{eV}$ from DFT calculations and a pre-factor of $6 \times 10^{12} \mathrm{~s}^{-1}$ to describe the migration of $\mathrm{H}$ atoms between two adjacent TIS sites in our model. The clustering of $\mathrm{H}$ atoms is ignored due to the fact that the binding energy of two $\mathrm{H}$ atoms is only $0.02 \mathrm{eV}$ at two $1 \mathrm{NN}$ TIS sites in $\mathrm{W}$ [26]. The capture radius for a single $\mathrm{H}$ atom is set as $3.0 \AA$ [19].

\section{4 Parameterisation of hydrogen-vacancy clusters}

The interaction of $\mathrm{H}$ with $\mathrm{V}$ has been widely discussed. Johnson and Carter [29] showed that a $\mathrm{V}_{1}$ can trap six $\mathrm{H}$ atoms by taking the ZPE into account in calculating the binding energies. Recently, the binding energies of $\mathrm{H}$ to $\mathrm{H}_{\mathrm{m}} \mathrm{V}_{\mathrm{n}}$ clusters were thoroughly investigated by Valles et al. [9] using the DFT method. They proposed a simple formula to estimate the binding energies of $\mathrm{H}_{\mathrm{m}} \mathrm{V}_{\mathrm{n}}$ clusters as $E_{b}=1.04$ 
$\times(m / n)^{-0.43}$ for the process of $H+V \rightarrow H_{m-1} V_{n}$, where $m$ and $n$ is the number of $\mathrm{H}$ and $\mathrm{V}$ in the cluster, respectively. Note that this formula may be only accurate when the number of $\mathrm{V}$ is less than 5 since the formula is fitted to $\mathrm{H}_{\mathrm{m}} \mathrm{V}_{1-5}$ clusters. Using $\mathrm{MS}$ and four different potentials, Wang et al. [10] systematically investigated the interaction of $\mathrm{H}$ with $\mathrm{V}_{1-10}$, then with $\mathrm{V}_{40}$ [11]. They obtained a logarithmic function of $E_{b}=\ln \left(c_{1}+c_{2} \times m\right)$ for the binding energies of the $\mathrm{m}^{\text {th }} \mathrm{H}$, where $c_{1}$ and $c_{2}$ are fitting parameters. The radius of the $\mathrm{H}_{\mathrm{m}} \mathrm{V}_{\mathrm{n}}$ cluster is assumed to be the same as that of the $\mathrm{V}_{\mathrm{n}}$ cluster since the volume of the $\mathrm{H}$ atom is very small. In this work, we consider the sizes of vacancy clusters from $V_{1}$ to $V_{40}$ in order to study the clustering behavior of $H$ and $V$. The binding energies of $H_{m} V_{n}$ clusters are listed in Table 1. The binding energies of $\mathrm{H}_{\mathrm{m}} \mathrm{V}_{1}$ are taken from DFT results [8]. The binding energies of $\mathrm{H}_{\mathrm{m}} \mathrm{V}_{2-10}$ are taken from Ref. [10]. The binding energies of other $\mathrm{H}_{\mathrm{m}} \mathrm{V}_{15,20,30}$ clusters are obtained by using an interpolation function based on known binding energies of $\mathrm{H}_{\mathrm{m}} \mathrm{V}_{15,22,40}$ [11]. The calculation deails can be found in Section 3.1.

Table 1. Binding energies $\left(\mathrm{E}_{\mathrm{b}}\right)$ of $\mathrm{H}$ with $\mathrm{H}_{\mathrm{m}-1} \mathrm{~V}_{\mathrm{n}}$ clusters

\begin{tabular}{lll}
\hline Cluster & $\mathrm{E}_{\mathrm{b}}$ & Ref. \\
$\mathrm{H}_{\mathrm{m}} \mathrm{V}_{2}\left(\mathrm{H}+\mathrm{H}_{\mathrm{m}-1} \mathrm{~V}_{2}\right)$ & $\ln (-0.2001 \times \mathrm{m}+3.4287)$ & {$[10]$} \\
$\mathrm{H}_{\mathrm{m}} \mathrm{V}_{3}\left(\mathrm{H}+\mathrm{H}_{\mathrm{m}-1} \mathrm{~V}_{3}\right)$ & $\ln (-0.1440 \times \mathrm{m}+3.4589)$ & {$[10]$} \\
$\mathrm{H}_{\mathrm{m}} \mathrm{V}_{4}\left(\mathrm{H}+\mathrm{H}_{\mathrm{m}-1} \mathrm{~V}_{4}\right)$ & $\ln (-0.1171 \times \mathrm{m}+3.5004)$ & {$[10]$} \\
$\mathrm{H}_{\mathrm{m}} \mathrm{V}_{5}\left(\mathrm{H}+\mathrm{H}_{\mathrm{m}-1} \mathrm{~V}_{5}\right)$ & $\ln (-0.0877 \times \mathrm{m}+3.2499)$ & {$[10]$} \\
$\mathrm{H}_{\mathrm{m}} \mathrm{V}_{6}\left(\mathrm{H}+\mathrm{H}_{\mathrm{m}-1} \mathrm{~V}_{6}\right)$ & $\ln (-0.0772 \times \mathrm{m}+3.3217)$ & {$[10]$} \\
$\mathrm{H}_{\mathrm{m}} \mathrm{V}_{7}\left(\mathrm{H}+\mathrm{H}_{\mathrm{m}-1} \mathrm{~V}_{7}\right)$ & $\ln (-0.0637 \times \mathrm{m}+3.2375)$ & {$[10]$} \\
$\mathrm{H}_{\mathrm{m}} \mathrm{V}_{8}\left(\mathrm{H}+\mathrm{H}_{\mathrm{m}-1} \mathrm{~V}_{8}\right)$ & $\ln (-0.0580 \times \mathrm{m}+3.2659)$ & {$[10]$} \\
$\mathrm{H}_{\mathrm{m}} \mathrm{V}_{9}\left(\mathrm{H}+\mathrm{H}_{\mathrm{m}-1} \mathrm{~V}_{9}\right)$ & $\ln (-0.0570 \times \mathrm{m}+3.1999)$ & {$[10]$} \\
$\mathrm{H}_{\mathrm{m}} \mathrm{V}_{10}\left(\mathrm{H}+\mathrm{H}_{\mathrm{m}-1} \mathrm{~V}_{10}\right)$ & $\ln (-0.0568 \times \mathrm{m}+3.2114)$ & {$[10]$} \\
\hline
\end{tabular}




\begin{tabular}{lll}
\hline $\mathrm{H}_{\mathrm{m}} \mathrm{V}_{15}\left(\mathrm{H}+\mathrm{H}_{\mathrm{m}-1} \mathrm{~V}_{15}\right)$ & $\ln (-0.0149 \times \mathrm{m}+3.1832)$ & {$[11]$} \\
$\mathrm{H}_{\mathrm{m}} \mathrm{V}_{22}\left(\mathrm{H}+\mathrm{H}_{\mathrm{m}-1} \mathrm{~V}_{22}\right)$ & $\ln (-0.0248 \times \mathrm{m}+3.1749)$ & {$[11]$} \\
$\mathrm{H}_{\mathrm{m}} \mathrm{V}_{40}\left(\mathrm{H}+\mathrm{H}_{\mathrm{m}-1} \mathrm{~V}_{40}\right)$ & $\ln (-0.0330 \times \mathrm{m}+3.1139)$ & {$[11]$} \\
\hline
\end{tabular}

The OKMC simulations presented in this work were performed using our in-house code. The simulation box was set as $100 a_{0} \times 100 a_{0} \times 100 a_{0}$, where $a_{0}$ is the lattice parameter of $\mathrm{W}, 3.14 \AA$. All defects were randomly introduced in the simulation box. Each simulation was run for a enough long time to reach the equilibrium state of the system.

\section{Results and discussion}

In this section, we present the main OKMC simulation results with some relevant discussions. The determination of successive binding energies of $\mathrm{H}_{\mathrm{m}} \mathrm{V}_{\mathrm{n}}$ clusters are presented first in section 3.1. Then in section 3.2, we show the effect of the temperature on the clustering behaviour of $\mathrm{H}$ with $\mathrm{V}$ or $\mathrm{V}$ clusters. Finally, we explore the effect of $\mathrm{H}$ concentration on the formation of $\mathrm{H}_{\mathrm{m}} \mathrm{V}_{\mathrm{n}}$ clusters.

\subsection{Determination of $\boldsymbol{H}$ successive binding energy with $V$ clusters}

A typical OKMC simulation requires a complete database for all kinds of defects that may occur during the simulation. In this work, to describe the traping behaviour of $\mathrm{H}$ with $\mathrm{V}_{\mathrm{n}}(\mathrm{n}=1-30)$ clusters, the corresponding binding energies have to be pre-determined. Thanks to the DFT and MS simulations, successive binding energies of some $\mathrm{H}_{\mathrm{m}} \mathrm{V}_{\mathrm{n}}$ clusters have already been obtained: the successive binding energies of $\mathrm{H}$ atoms to $\mathrm{V}_{1}$ were obtained by DFT calculations [8]. For large clusters, by analyzing the MS simulation data, Wang et al. [10,11] found that the successive binding energies of $H$ to $H_{m} V_{n}$ clusters show a logarithmic relationship of $E_{b}=\ln \left(c_{1}+c_{2} \times m\right)$, where constants $c_{1}$ and $c_{2}$ are fitting parameters. In this work, we assumed that the binding energies of other $\mathrm{H}_{\mathrm{m}} \mathrm{V}_{11-40}$ clusters follow the same relationship, thus their binding energies can be determined based on this logarithmic relationship. The fitted binding energy of $\mathrm{m}^{\text {th }} \mathrm{H}$ atom to $\mathrm{H}_{\mathrm{m}-1} \mathrm{~V}_{15,20,30}$ cluster is determined to be $\ln (-0.0540 \times \mathrm{m}+$ $3.8000), \ln (-0.0291 \times \mathrm{m}+3.2520)$, and $\ln (-0.0286 \times \mathrm{m}+3.7900)$, respectively. The calculated 
successive binding energies of $\mathrm{H}_{m} \mathrm{~V}_{\mathrm{n}}$ clusters as a function of trapped $\mathrm{H}$ atoms are depicted in Fig. 1 (a). It can be seen from Fig. 1 (a) that the successive binding energies of $\mathrm{H}$ to $\mathrm{H}_{\mathrm{m}-1} \mathrm{~V}_{\mathrm{n}}$ clusters decrease when the number of $\mathrm{H}$ atoms increases. Positive binding energies indicate the attraction of $\mathrm{H}$ with $\mathrm{V}$ or $\mathrm{V}$ clutsers while negative ones indicate the repulsion of them. Thus, the intersection points between the curve of the number of trapped $\mathrm{H}$ and the zero binding energy give the maximum number of trapped $\mathrm{H}$ in $\mathrm{V}$ or $\mathrm{V}$ cluster. Accordingly, we also plot the maximum number of trapped $\mathrm{H}$ atoms in Fig. 1 (b).

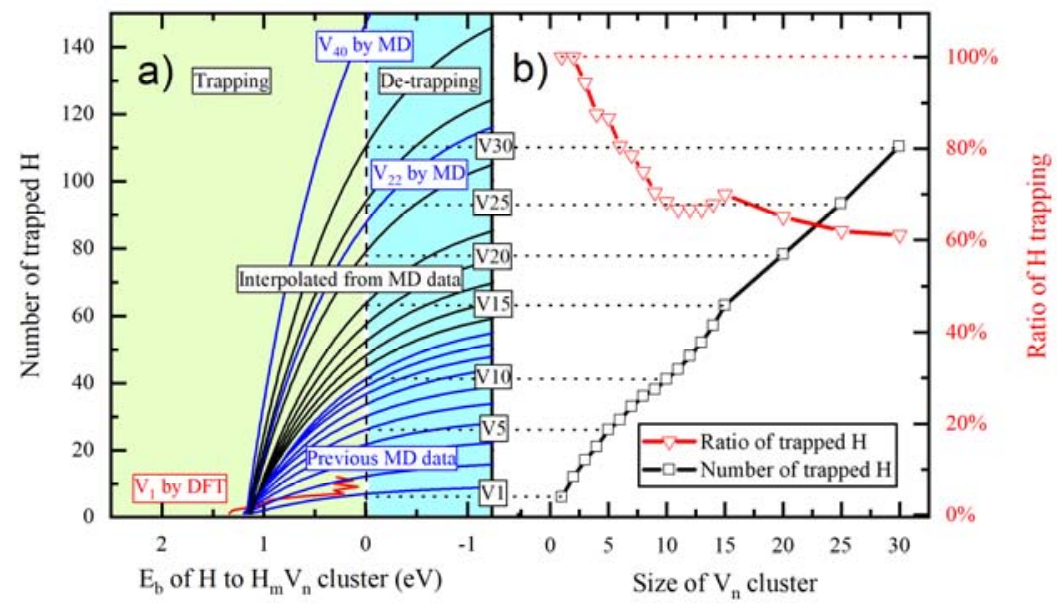

Figure 1. (a) Number of trapped $\mathrm{H}$ in $\mathrm{H}_{\mathrm{m}} \mathrm{V}_{\mathrm{n}}$ clusters for $\mathrm{V}_{1-40}$ as a function of their binding energies. (b) Number and ratio of trapped $\mathrm{H}$ as a function of $\mathrm{V}$ clusters size at temperature of $0 \mathrm{~K}$ (black square). And the ratio of trapped $\mathrm{H}$ with the same $\mathrm{V}$ concentration (red triangles). Here the ratio $x_{n}$ of trapped $\mathrm{H}$ is defined as $\mathrm{N}_{\mathrm{Vn}} / \mathrm{N}_{\mathrm{V} 1}$, where $\mathrm{N}_{\mathrm{V} 1}$ is the number of total trapped $\mathrm{H}$ by $\mathrm{V}_{1}$ and $\mathrm{N}_{\mathrm{Vn}}$ is the number of total trapped $\mathrm{H}$ by $\mathrm{V}_{\mathrm{n}}$ at $0 \mathrm{~K}$.

In order to demonstrate the trapping ability of various $\mathrm{V}_{\mathrm{n}}$ clusters for $\mathrm{H}$ atoms, we define a ratio of trapped $\mathrm{H}$ as $x_{n}=\mathrm{N}_{\mathrm{Vn}} / \mathrm{N}_{\mathrm{V} 1}$, where $\mathrm{n}$ is the number of vacancies in the cluster, $\mathrm{N}_{\mathrm{V} 1}$ is the number of the total trapped $\mathrm{H}$ by $\mathrm{V}_{1}$, and $\mathrm{N}_{\mathrm{Vn}}$ is the number of the total trapped $\mathrm{H}$ by $\mathrm{V}_{\mathrm{n}}$ cluster. The results are given in Fig. 1(b). It clearly show that the trapping ability of $\mathrm{V}$ clusters to $\mathrm{H}$ drops dramatically with increasing of the number of $\mathrm{V}$ in clusters if the total amount of $\mathrm{V}$ is kept the same. For example, for the 
$\mathrm{V}_{30}$ cluster, the number of total trapped $\mathrm{H}$ drops by $40 \%$ compared with that for $\mathrm{V}_{1}$. We should point out, however, that all these results were obtained at temperature $0 \mathrm{~K}$, and the effect of temperature will be investigated in the next section.

\subsection{Effect of temperature on trapping of $H$ by $H_{m} V_{n}$ clusters}

In this section, we studied the effect of temperature on the clustering behaviour of $H$ with $V_{1}, V_{2}$, and large V clusters in W. Three temperatures of $300 \mathrm{~K}, 600 \mathrm{~K}$, and $1000 \mathrm{~K}$ were used in our simulations. They correspond to three typical temperatures in fusion reactors. $300 \mathrm{~K}$ was considered as room temperature in our stimulation, while $600 \mathrm{~K}$ is the typical working temperature of the plasma facing materials [30-32]. The temperature of the tungsten divertor monoblock can be as high as 1000-2000 K estimated by simulations in Ref. [30-32], so $1000 \mathrm{~K}$ was considered as the high temperature in our stimulation.

\subsubsection{Trapping behaviour of $H$ by monovacancies}

$\mathrm{H}$ atoms can be de-trapped from $\mathrm{H}_{\mathrm{m}} \mathrm{V}_{1}$ clusters when the temperature is high enough. To study the effect of the temperature on the trapping behaviour of $\mathrm{H}$ by $\mathrm{V}$ clusters, we first simulated monovacancies with $\mathrm{H}$ atoms at three typical temperatures $300 \mathrm{~K}, 600 \mathrm{~K}$, and $1000 \mathrm{~K}$. The initial monovacancies and $\mathrm{H}$ atoms are randomly distributed in the simulation domain. Based on the DFT results [8], a monovacancy can trap up to $12 \mathrm{H}$ atoms. The initial ratio of $\mathrm{V}$ to $\mathrm{H}$ was set to be $1: 12$, so its concentration is 30 and 360 atomic-parts-per-million (appm), respectively. The selected concentration of $\mathrm{V}$ is within the range of both simulation and experimental results. For example, several DFT stimulation results showed that the concentration of vacancy can vary from $0.1 \mathrm{appm}$ to $1000 \mathrm{appm}$ when $\mathrm{H}$ changes from 1 to 1000 appm. [33,34]. There are few experimental reports on the concentration of $\mathrm{V}$ because of its difficulty to be measured directly. $\mathrm{Xu}$ et. al. [35] measured the post-irradiation $\mathrm{V}$ concentration to be 15-55 appm at the temperatures ranging from $300 \mathrm{~K}$ to $1000 \mathrm{~K}$. In this work, we fix the vacancy concentration to be 30 appm for simplicity. We then perform a series of simulations to study the evolution of $\mathrm{H}_{\mathrm{m}} \mathrm{V}_{1}$ clusters at various temperatures. For each temperature, the calculated fraction of 
$\mathrm{H}_{\mathrm{m}} \mathrm{V}_{1}$ clusters as a function of time was obtained by averaging 20 separate simulation runs, where the random number seeds and initial positions of defects are varied in each simulation run.
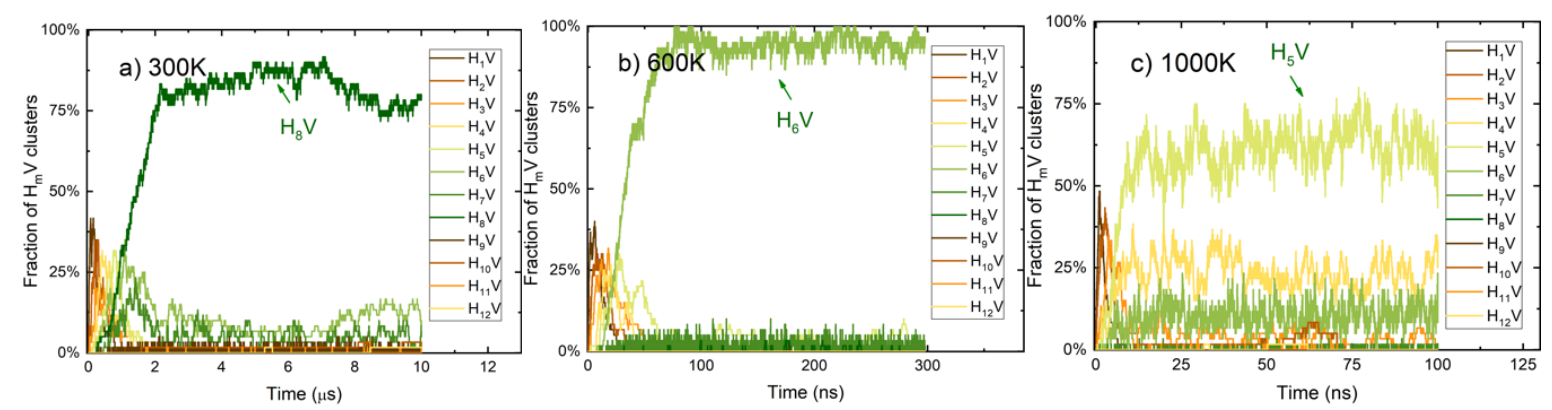

Figure 2. Fraction of the $\mathrm{H}_{\mathrm{m}} \mathrm{V}_{1}$ cluster as a function of time at temperatures of (a) $300 \mathrm{~K}$, (b) $600 \mathrm{~K}$, and (c) $1000 \mathrm{~K}$, respectively. The fraction of the $\mathrm{H}_{\mathrm{m}} \mathrm{V}_{1}$ cluster is defined as the ratio of number of $\mathrm{H}_{\mathrm{m}} \mathrm{V}_{1}$ clusters with respect to the initial number of monovacancies.

Figure 2 shows the fractions of $\mathrm{H}_{\mathrm{m}} \mathrm{V}_{1}(\mathrm{~m}=1, \ldots, 12)$ clusters as a function of time at three temperatures. The fraction of $\mathrm{H}_{\mathrm{m}} \mathrm{V}_{1}$ clusters is defined as the ratio of number of $\mathrm{H}_{\mathrm{m}} \mathrm{V}_{1}$ clusters with respect to the initial number of monovacancies. It can be seen that the small $\mathrm{H}_{\mathrm{m}} \mathrm{V}_{1}$ clusters form first and then continue to trap more $\mathrm{H}$ atoms to grow their sizes. After a certain time, stable $\mathrm{H}_{\mathrm{m}} \mathrm{V}_{1}$ clusters are formed and their fractions are nearly independent on the time. Unstable $\mathrm{H}_{\mathrm{m}} \mathrm{V}_{1}$ clusters disappear and their fractions approach to zero. Our simulations show the most stable cluster is $\mathrm{H}_{8} \mathrm{~V}_{1}, \mathrm{H}_{6} \mathrm{~V}_{1}$, and $\mathrm{H}_{5} \mathrm{~V}_{1}$ at $300 \mathrm{~K}, 600 \mathrm{~K}$, and $1000 \mathrm{~K}$, respectively, whereas the DFT calculations [8] indicate that a single vacancy can trap up to $12 \mathrm{H}$ atoms. This means that the trapping behaviour of $\mathrm{H}$ by the monovacancy is significantly affected by temperature. The reason can be attributed to the increased de-trapping probability of $\mathrm{H}$ from the $\mathrm{H}_{\mathrm{m}} \mathrm{V}_{1}$ clusters at high temperature. For the temperature of $300 \mathrm{~K}$, the most stable cluster is $\mathrm{H}_{8} \mathrm{~V}_{1}, \mathrm{H}$ atoms can be easily emitted from $\mathrm{H}_{9-12} \mathrm{~V}_{1}$ clusters because their binding energies are close to zero. Thus, $\mathrm{H}_{9-12} \mathrm{~V}$ clusters disappear and $\mathrm{H}_{8} \mathrm{~V}$ clusters are stabilized. At $600 \mathrm{~K}, \mathrm{H}_{6} \mathrm{~V}_{1}$ is the most stable cluster. All other $\mathrm{H}_{\mathrm{m}} \mathrm{V}_{1}$ clusters disappear. For the temperature of $1000 \mathrm{~K}$, four clusters 
including $\mathrm{H}_{3} \mathrm{~V}_{1}, \mathrm{H}_{4} \mathrm{~V}_{1}, \mathrm{H}_{5} \mathrm{~V}_{1}$, and $\mathrm{H}_{6} \mathrm{~V}_{1}$ are stable. Among them, $\mathrm{H}_{5} \mathrm{~V}_{1}$ has the largest volume fraction. At $300 \mathrm{~K}$, all $\mathrm{H}$ atoms are trapped in $\mathrm{H}_{8} \mathrm{~V}_{1}$ clusters, while the number of trapped $\mathrm{H}$ atoms drops to about $50 \%$ at $1000 \mathrm{~K}$. This is because the binding energies of $\mathrm{H}_{\mathrm{m}} \mathrm{V}_{1}$ with $\mathrm{H}$ atoms continuously decrease with $\mathrm{H}_{\mathrm{m}} \mathrm{V}_{1}$ trapping more $\mathrm{H}$ atoms. The last trapped $\mathrm{H}$ atoms are thus very unstable due to their relatively small binding energies. With increasing temperature, those $\mathrm{H}$ atoms can be easily de-trapped from the $\mathrm{H}_{\mathrm{m}} \mathrm{V}_{1}$ clusters and become mobile interstitials in W. Comparing with our previous results that used the binding energies without considering the ZPE [18], we find that the number of $\mathrm{H}$ atoms trapped by $\mathrm{H}_{\mathrm{m}} \mathrm{V}_{1}$ clusters decreases for all temperatures when the ZPE is taken into account. For example, at $300 \mathrm{~K}$ the size of $\mathrm{H}_{\mathrm{m}} \mathrm{V}_{1}$ drops from $\mathrm{H}_{10} \mathrm{~V}_{1}$ (without $\mathrm{ZPE}$ ) to $\mathrm{H}_{8} \mathrm{~V}_{1}$ (with $\mathrm{ZPE}$ ), at $600 \mathrm{~K}$ from $\mathrm{H}_{9} \mathrm{~V}_{1}$ (without $\mathrm{ZPE}$ ) to $\mathrm{H}_{6} \mathrm{~V}_{1}$ (with $\mathrm{ZPE}$ ), and at $1000 \mathrm{~K}$ from $\mathrm{H}_{5-7} \mathrm{~V}_{1}$ (without $\mathrm{ZPE}$ ) to $\mathrm{H}_{4-6} \mathrm{~V}_{1}$ (with $\mathrm{ZPE}$ ). The required time for reaching the equilibrium of the system is largely dependent on temperature. It is about 10 microseconds at $300 \mathrm{~K}$, while it is around 25 nanoseconds at $1000 \mathrm{~K}$. This is because the possibilities of events increase at high temperature, which shorten the time of the events based on Eq. (2).

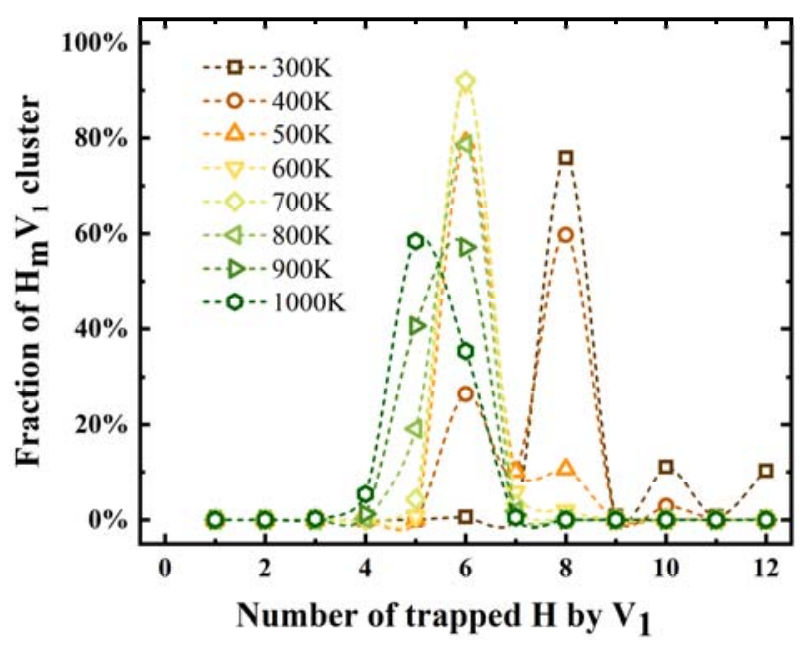

Figure 3. Fraction of the $\mathrm{H}_{\mathrm{m}} \mathrm{V}_{1}$ cluster as a function of the number of trapped $\mathrm{H}$ at temperatures ranging from $300 \mathrm{~K}$ to $1000 \mathrm{~K}$. The fraction of the $\mathrm{H}_{\mathrm{m}} \mathrm{V}_{1}$ cluster is defined as the ratio of number of the $\mathrm{H}_{\mathrm{m}} \mathrm{V}_{1}$ clusters with respect to the initial number of $\mathrm{V}$. 
Figure 3 shows the fractions of $\mathrm{H}_{\mathrm{m}} \mathrm{V}_{1}$ clusters as a function of the number of trapped $\mathrm{H}$ by monovacancies at temperatures ranging from $300 \mathrm{~K}$ to $1000 \mathrm{~K}$. It can be seen that the number of trapped $\mathrm{H}$ atoms by monovacancies decreases with the increase of temperature, which is consistent with previous results $[34,36]$. As expected, more $\mathrm{H}$ atoms are emitted at high temperatures than at low temperatures.

\subsubsection{Trapping behaviour of $H$ by di-vacancies}

With the same conditions as above, we further examined the effect of temperature on the clustering behaviour of $\mathrm{H}$ atoms with di-vacancies. For the purpose of comparison, the concentrations of $\mathrm{H}$ and $\mathrm{V}$ are set as the same as previous simulations used. Thus, the number of di-vacancies in this new set of simulations is exactly half number of the mono-vacancies in the previous calculations. Figure 4 shows the fractions of $\mathrm{H}_{\mathrm{m}} \mathrm{V}_{2}$ clusters as a function of time. In general, the fractions of $\mathrm{H}_{\mathrm{m}} \mathrm{V}_{2}$ clusters exhibit similar trends as shown in Fig. 2. Small $\mathrm{H}_{\mathrm{m}} \mathrm{V}_{2}$ clusters form first, and then they attract more $\mathrm{H}$ atoms to grow to large $\mathrm{H}_{\mathrm{m}} \mathrm{V}_{2}$ clusters. The most stable $\mathrm{H}_{\mathrm{m}} \mathrm{V}_{2}$ clusters obtained are $\mathrm{H}_{11} \mathrm{~V}_{2}, \mathrm{H}_{9,10} \mathrm{~V}_{2}$, and $\mathrm{H}_{7,8,9} \mathrm{~V}_{2}$ at $300 \mathrm{~K}, 600 \mathrm{~K}$, and $1000 \mathrm{~K}$, respectively, which clearly indicates that the trapping ability of $\mathrm{H}_{\mathrm{m}} \mathrm{V}_{2}$ decreases with increasing temperature. According to the binding energies of mono-vacancies obtained from DFT and di-vicancies from MS calculations, both of which can trap $12 \mathrm{H}$. As a result, more $\mathrm{H}$ atoms remain mobile for the case of di-vacancies than the ones for mono-vacancies at the same temperature.
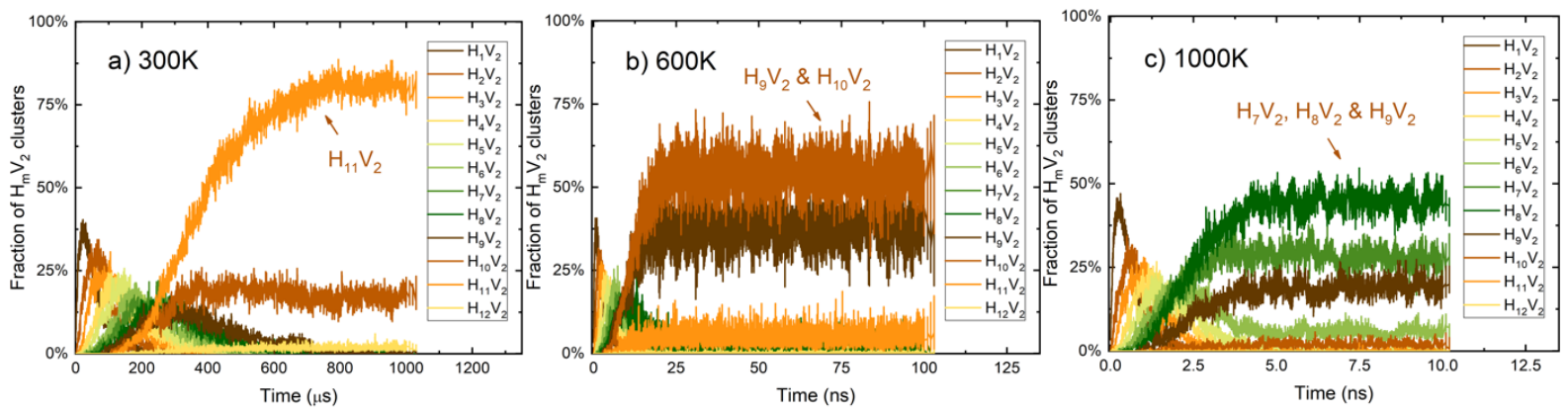
Figure 4. Fraction of the $\mathrm{H}_{m} \mathrm{~V}_{2}$ cluster as a function of time at temperatures of (a) $300 \mathrm{~K}$, (b) 600 $\mathrm{K}$, and (c) $1000 \mathrm{~K}$, respectively. Fraction of the $\mathrm{H}_{\mathrm{m}} \mathrm{V}_{2}$ cluster is defined as the ratio of number of the $\mathrm{H}_{\mathrm{m}} \mathrm{V}_{2}$ cluster with respect to the initial number of di-vacancies.

A more detailed information on $\mathrm{H}_{\mathrm{m}} \mathrm{V}_{2}$ clusters at temperatures ranging from $300 \mathrm{~K}$ to $1000 \mathrm{~K}$ is given in Fig. 5. As the temperature increases, more stable $\mathrm{H}_{\mathrm{m}} \mathrm{V}_{2}$ clusters have a smaller number of $\mathrm{H}$ atoms. Furthermore, the fraction of $\mathrm{H}$ atoms outside $\mathrm{H}_{\mathrm{m}} \mathrm{V}_{2}$ clusters increases with increasing temperature.

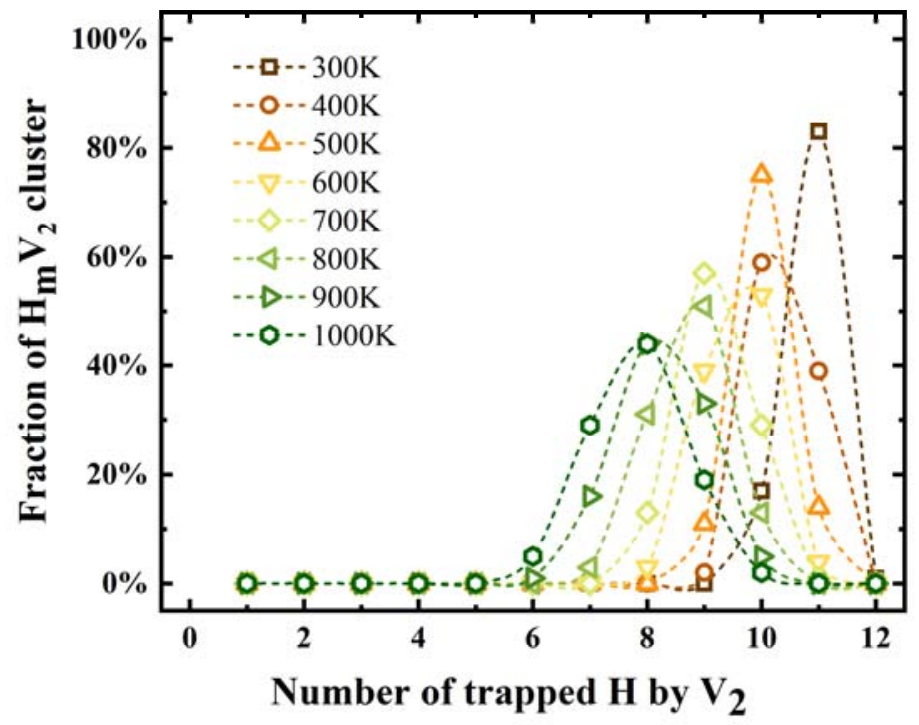

Figure 5. Fraction of the $\mathrm{H}_{\mathrm{m}} \mathrm{V}_{2}$ cluster as a function of temperatures ranging from $300 \mathrm{~K}$ to $1000 \mathrm{~K}$. Fraction of the $\mathrm{H}_{\mathrm{m}} \mathrm{V}_{2}$ cluster is defined as the ratio of number of the $\mathrm{H}_{\mathrm{m}} \mathrm{V}_{2}$ clusters with respect to the initial number of $\mathrm{V}$.

\subsubsection{Trapping behaviour of $H$ by large $V$ clusters}

Formation of V clusters is often observed in irradiated $\mathrm{W}$ in experiments. For example, Eleveld et al. [37] observed stable $\mathrm{V}_{11-16}$ clusters after heating at $650 \mathrm{~K}$ for the $30 \mathrm{keV} \mathrm{D}_{2}$ ion irradiated samples at room temperature. Ferroni et al. [38] reported a similar observation of V clusters in W irradiated with 2 
$\mathrm{MeV} \mathrm{W}$ ion. We then study the clustering behaviour of $\mathrm{H}$ atoms with $\mathrm{V}$ clusters. Different initial $\mathrm{V}_{\mathrm{n}}$ clusters size of $n=1-30$ are used and their initial concentrations $\left(C_{V}\right)$ are set as 30 appm. The initial $H$ concentration $\left(\mathrm{C}_{\mathrm{H}}\right)$ is set as $\mathrm{C}_{\mathrm{v}}$ multiplied by the number of maximum trapped $\mathrm{H}$ atoms at $0 \mathrm{~K}\left(\mathrm{~N}_{\mathrm{Vn}}{ }^{0}\right)$ for each cluster, which has an expression of $\mathrm{C}_{\mathrm{V}} \times \mathrm{N}_{\mathrm{Vn}_{\mathrm{n}}}$. Figure 6 shows the average number of trapped $\mathrm{H}$ atoms as a function of temperature for six selected $\mathrm{V}$ clusters. The average number of trapped $\mathrm{H}$ atoms in V clusters decreases with the increase of temperature for all cases. This is due to the increased detrapping probabilities with temperature. The average number of trapped $\mathrm{H}$ atoms for each type of $\mathrm{V}$ clusters is almost proportional to temperature except for mono-vacancies. For mono-vacancies, the binding energies of $\mathrm{H}_{6} \mathrm{~V}_{1}$ clusters with $\mathrm{H}$ atoms are only about $0.2 \mathrm{eV}$ according to DFT calculations [8]. Thus, the $\mathrm{H}_{7-12} \mathrm{~V}_{1}$ clusters are very unstable and $\mathrm{H}$ atoms can be easily de-trapped with increasing temperature, resulting in stable clusters $\mathrm{H}_{8} \mathrm{~V}_{1}$ at $300 \mathrm{~K}, \mathrm{H}_{6} \mathrm{~V}_{1}$ at $600 \mathrm{~K}$, and $\mathrm{H}_{6} \mathrm{~V}_{1}$ at $1000 \mathrm{~K}$. When the size of the $\mathrm{V}$ clusters increases, the average number of trapped $\mathrm{H}$ atoms in $\mathrm{V}$ clusters decreases largely for small $\mathrm{V}$ clusters but changes slightly for large ones. For example, clusters $\mathrm{V}_{10}, \mathrm{~V}_{15}, \mathrm{~V}_{20}$, and $\mathrm{V}_{30}$ can trap three $\mathrm{H}$ atoms at $300 \mathrm{~K}$ and two $\mathrm{H}$ atoms at $1000 \mathrm{~K}$. Thus, we can expect that the average number of trapped $\mathrm{H}$ atoms around three $\mathrm{H}$ atoms at $300 \mathrm{~K}$ and two $\mathrm{H}$ atoms at $1000 \mathrm{~K}$ with the size of $\mathrm{V}$ clusters is larger than 30 . 


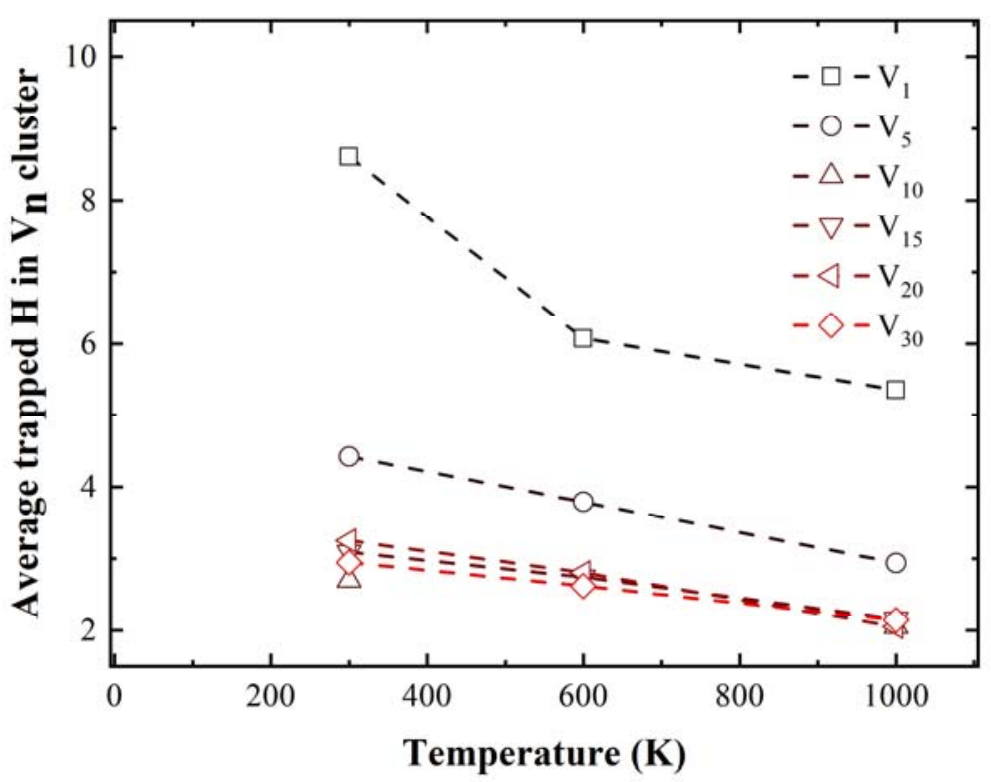

Figure 6. Average number of trapped $\mathrm{H}$ atoms by $\mathrm{V}_{1,5,10,15,20,30}$ clusters as a function of temperature of $300 \mathrm{~K}, 600 \mathrm{~K}$, and $1000 \mathrm{~K}$.

\subsection{Effect of $H$ concentration and $V$ cluster size on the clustering}

The initial $\mathrm{H}$ concentration can have a great impact on the clustering behaviour of $\mathrm{H}_{\mathrm{m}} \mathrm{V}_{\mathrm{n}}$. To study the effect of $\mathrm{H}$ concentration on the clustering of $\mathrm{V}$, we performed a series of simulations with varing the $\mathrm{H}$ concentration from 50 to 1000 appm. The initial $\mathrm{V}_{\mathrm{n}}$ clusters are randomly distributed in the simulation box with the same concentration of $\mathrm{V}$ for all $\mathrm{V}_{\mathrm{n}}$ cases. Our study suggests that the maximum number of $\mathrm{H}$ captured by vacancy defects increases rapidly when the concentration of $\mathrm{H}$ is low, but reaches an equilibrium value with further increasing the $\mathrm{H}$ concentration. By setting the initial $\mathrm{H}$ concentration above the equilibrium value, we can study the effect of vacancy size on the clustering behaviors of $\mathrm{H}_{\mathrm{m}} \mathrm{V}_{\mathrm{n}}$ clusters.

\subsubsection{Effect of $H$ concentration on the clustering of $H_{m} V_{n}$}


A series of simulations of selected $\mathrm{V}$ clusters with different initial $\mathrm{H}$ concentrations have been carried out at temperatures of $300 \mathrm{~K}, 600 \mathrm{~K}$, and $1000 \mathrm{~K}$, respectively. In order to demonstrate how many $\mathrm{H}$ atoms are trapped by $\mathrm{V}$ clusters, we define the fraction of trapped $\mathrm{H}$ atoms as $p_{n}=\mathrm{N}_{\mathrm{Vn}}{ }^{\mathrm{T}} / \mathrm{N}_{\mathrm{V} 1}{ }^{0}$, where $\mathrm{N}_{\mathrm{Vn}}{ }^{\mathrm{T}}$ is the average number of trapped $\mathrm{H}$ by each $\mathrm{V}_{\mathrm{n}}$ at the temperature of the simulation, and $\mathrm{N}_{\mathrm{V} 1}{ }^{0}$ is the total number of trapped $\mathrm{H}$ by $\mathrm{V}_{1}$ predicted by MS at $0 \mathrm{~K}$. The calculated fractions of trapped $\mathrm{H}$ atoms as a function of the initial $\mathrm{H}$ concentration are shown in Fig. 7. Generally, the fraction of trapped $\mathrm{H}$ atoms increases when the $\mathrm{H}$ concentration increases at the beginning. It then changes gradually after the initial $\mathrm{H}$ concentration is larger than 250 appm for $300 \mathrm{~K}, 500$ appm for $600 \mathrm{~K}$, and 2000 appm for 1000 $\mathrm{K}$, respectively. This suggests that the effect of the initial $\mathrm{H}$ concentration for a long time evolution can be ignored when the initial $\mathrm{H}$ concentration is large enough. For each temperature, the maximum concentration of trapped $\mathrm{H}$ decreases when the sizes of $\mathrm{V}$ clusters increase, according to their binding energies. Specifically, at $300 \mathrm{~K}$, the fraction of trapped $\mathrm{H}$ for $\mathrm{V}_{1}$ increases rapidly when the initial concentration of $\mathrm{H}$ increases and then reaches a steady state after the $\mathrm{H}$ concentration reaches 1000 appm. $\mathrm{V}_{2-5}$ and $\mathrm{V}_{10,15,20,30}$ reach their equilibrium states quickly after 250 appm and their trapped $\mathrm{H}$ fractions are $40 \%$ and $30 \%$, respectively. At $600 \mathrm{~K}$, when the concentration of $\mathrm{H}$ is larger than 500 appm, the fraction of trapped $\mathrm{H}$ is about $50 \%$ for $\mathrm{V}_{1}$ while it is about $35 \%$ for $\mathrm{V}_{2-5}$ and $25 \%$ for $\mathrm{V}_{10,15,20,30 \text {. At }}$ $1000 \mathrm{~K}$, the fraction of the $\mathrm{H}$ concentration for $\mathrm{H}_{\mathrm{m}} \mathrm{V}_{1}$ is about $40 \%$, and for all other $\mathrm{V}$ clusters it is around $20-30 \%$. In general, the fraction of trapped $\mathrm{H}$ is large for the $\mathrm{H}_{\mathrm{m}} \mathrm{V}_{\mathrm{n}}$ clusters which contain little vacancies (i.e. small $\mathrm{n}$ ). It is also expected that the maximum number of trapped $\mathrm{H}$ atoms decreases when the temperature increases due to the increased probability of $\mathrm{H}$ emission. Therefore, the $\mathrm{H}$ saturation concentration for each V cluster has to be estimated for all temperatures. 


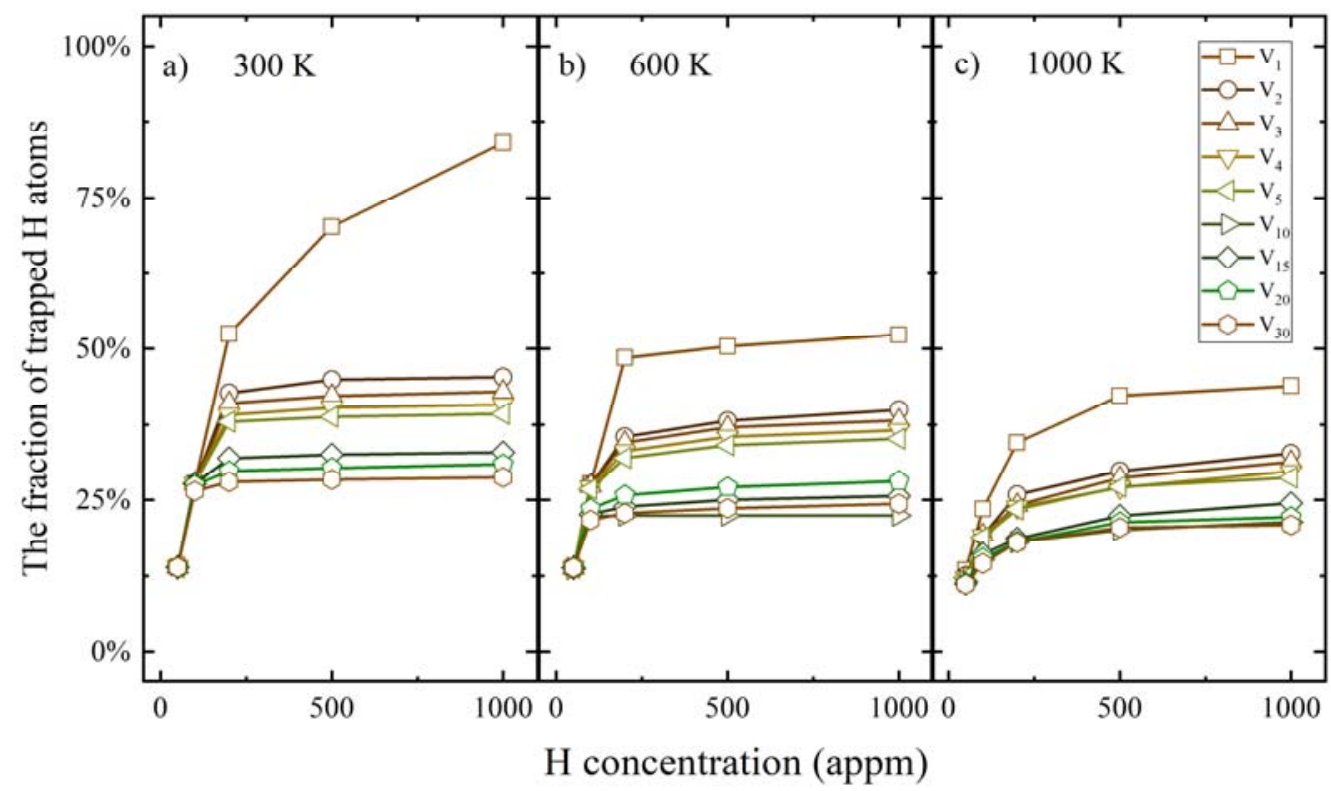

Figure 7. Fraction of trapped $\mathrm{H}$ atoms $x$ as a function of the initial $\mathrm{H}$ concentration at $300 \mathrm{~K}$ (a), $600 \mathrm{~K}(\mathrm{~b})$, and $1000 \mathrm{~K}$ (c). The fraction of trapped $\mathrm{H}$ atoms is defined as $\mathrm{N}_{\mathrm{Vn}_{\mathrm{n}}}{ }^{\mathrm{T}} / \mathrm{N}_{\mathrm{V} 1}{ }^{0}$, where $\mathrm{N}_{\mathrm{Vn}_{\mathrm{n}}}{ }^{\mathrm{T}}$ is the average number of the trapped $\mathrm{H}$ for each $\mathrm{V}_{\mathrm{n}}$ at elevated temperature, and $\mathrm{N}_{\mathrm{V} 1}{ }^{0}$ is the number of the total trapped $\mathrm{H}$ by $\mathrm{V}_{\mathrm{n}}$ predicted by MS at $0 \mathrm{~K}$.

\subsubsection{Effect of the $V$ cluster size on the clustering of $H_{m} V_{n}$}

With the determination of the $\mathrm{H}$ saturation concentration as shown in Fig. 7, we then study the effect of the $\mathrm{V}$ cluster size on the clustering behaviour of $\mathrm{H}_{\mathrm{m}} \mathrm{V}_{\mathrm{n}}$ under $\mathrm{H}$ saturation condition. Thus, the effect of $\mathrm{H}$ concentration on the clustering of $\mathrm{H}_{\mathrm{m}} \mathrm{V}_{\mathrm{n}}$ is considered to be very small. For this study, the initial $\mathrm{H}$ concentration is set to be $2000 \mathrm{appm}$, and the initial concentration of V clusters is $30 \mathrm{appm}$. Three different temperatures of $300 \mathrm{~K}, 600 \mathrm{~K}$, and $1000 \mathrm{~K}$ were chosen. Figure 8 shows the average number of trapped $\mathrm{H}$ atoms as a function of temperature for six selected $\mathrm{V}$ clusters with saturated $\mathrm{H}$ concentration and, as a comparison, with unsaturated $\mathrm{H}$ concentration (same as the results presented in Fig. 6). For a particular size of $\mathrm{V}_{\mathrm{n}}$ cluster, the number of trapped $\mathrm{H}$ atoms decreases when the temperature increases. 
This can be explained by the fact that the high temperature can increase the possibilities of $\mathrm{H}$ de-trapping events. The average number of trapped $\mathrm{H}$ atoms in the saturated $\mathrm{H}$ concentration case is much larger than the one in the unsaturated case for a fixed size of $V_{n}$ clusters. This is because $V_{n}$ clusters can trap as many $\mathrm{H}$ atoms as possible when a enough concentration of $\mathrm{H}$ is provied. As a consequence, every $\mathrm{V}_{\mathrm{n}}$ cluster will be filled with $\mathrm{H}$ atoms. Larger $\mathrm{V}_{\mathrm{n}}$ clusters can trap more $\mathrm{H}$ atoms on average since they have more rooms. Furthermore, for the saturated $\mathrm{H}$ concentration case, the average number of trapped $\mathrm{H}$ atoms in $\mathrm{V}$ clusters increases when the size of $\mathrm{V}$ clusters increases, in contrast with the unsaturated case as shown in Fig. 6. The reason is that larger $\mathrm{V}$ clusters can accommodate more $\mathrm{H}$ atoms than smaller $\mathrm{V}$ clusters when the saturated $\mathrm{H}$ concentration is provided. However, for the unsaturated $\mathrm{H}$ concentration case, the number of large $\mathrm{V}$ clusters is less than the number of small $\mathrm{V}$ clusters (as we assumed the total amount of $\mathrm{V}$ to be the same). Thus, the small number of large $\mathrm{V}$ clusters reduces the probability of forming $\mathrm{H}_{\mathrm{m}} \mathrm{V}_{\mathrm{n}}$ clusters when the $\mathrm{H}$ concentration is limited, which leads to the fact that the average number of trapped $\mathrm{H}$ atoms in $\mathrm{V}$ clusters decreases when the size of $\mathrm{V}$ clusters increases.

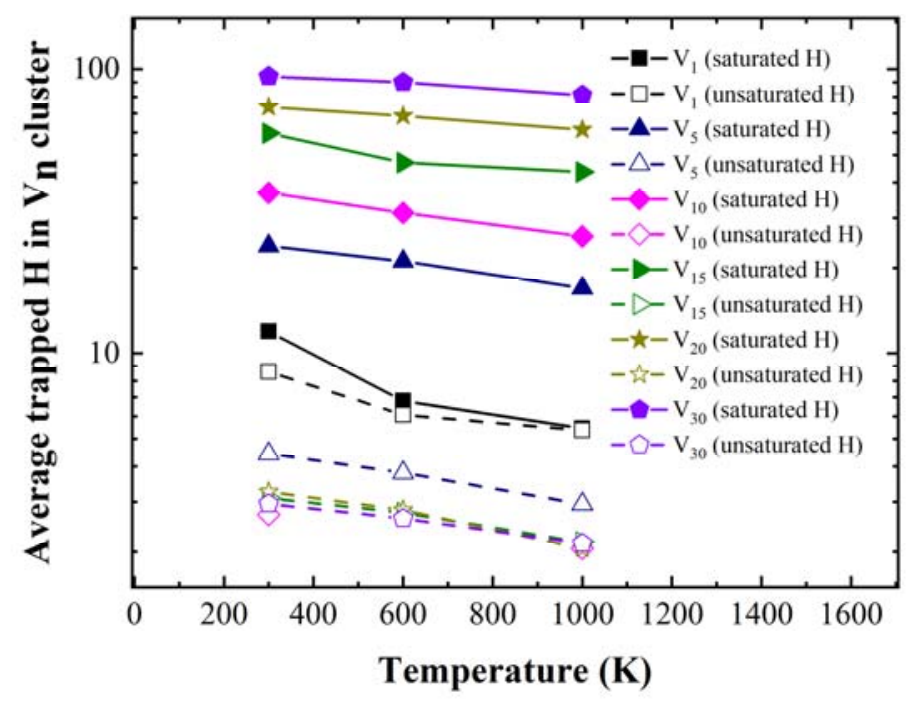

Figure 8. Average number of trapped $\mathrm{H}$ atoms by $\mathrm{V}_{1}, 5,10,15,20,30$ clusters as a function of temperature of $300 \mathrm{~K}, 600 \mathrm{~K}$, and $1000 \mathrm{~K}$. 
The calculated fractions of trapped $\mathrm{H}$ atoms as a function of $\mathrm{V}_{\mathrm{n}}$ size are shown in Fig. 9. The fraction of trapped $\mathrm{H}$ atoms is defined as the ratio of trapped $\mathrm{H}$ atoms with respect to the total number of $\mathrm{H}$ atoms. For a given temperature, the number of trapped $\mathrm{H}$ decreases when the sizes of $\mathrm{V}_{\mathrm{n}}$ clusters increase. It then changes gradually after $n=10$, which implies that the trapping capability of $\mathrm{H}_{\mathrm{m}} \mathrm{V}_{\mathrm{n}}$ clusters to $\mathrm{H}$ atoms decreases with the increase of the sizes of $\mathrm{H}_{\mathrm{m}} \mathrm{V}_{\mathrm{n}}$ clusters. Thus, compared to the trapping behaviour of $\mathrm{H}_{\mathrm{m}} \mathrm{V}_{\mathrm{n}}$ with $\mathrm{H}$ atoms with the unsaturated $\mathrm{H}$ concentration in Fig. 6, the clustering behaviour of $\mathrm{H}_{\mathrm{m}} \mathrm{V}_{\mathrm{n}}$ is mainly determined by the sizes of $\mathrm{V}$ clusters when the saturated $\mathrm{H}$ concentration is reached.

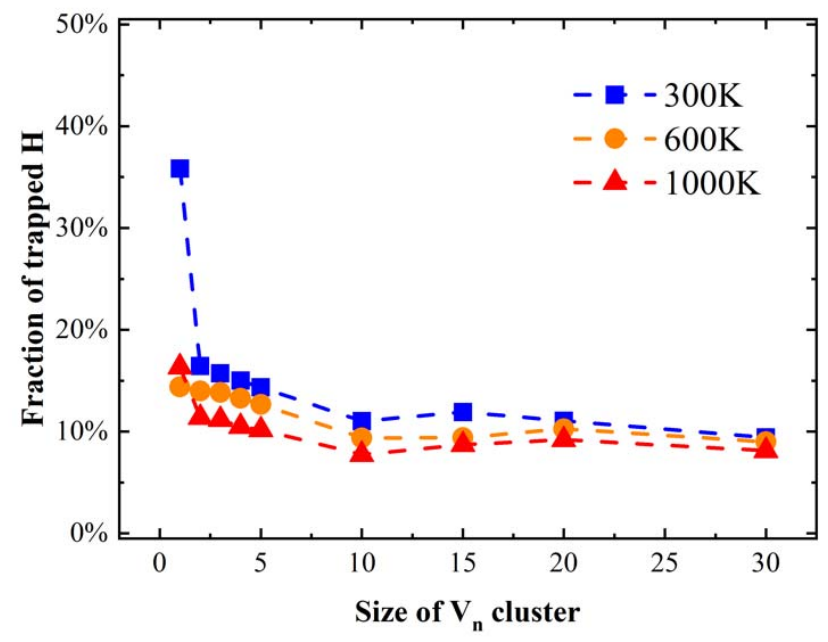

Figure 9. Fraction of trapped $\mathrm{H}$ atoms as a function of the vacancy size at three different temperatures of $300 \mathrm{~K}, 600 \mathrm{~K}$, and $1000 \mathrm{~K}$.

\subsubsection{Discussion}

At present, it is still a big challenge to estimate the $\mathrm{H}$ retention in irradiated $\mathrm{W}$ from experimental or simulation approaches [39]. The total $\mathrm{H}$ retention in $\mathrm{W}$ is a very complex phenomenon as it is impacted by many factors such as manufacturing processes, impurities, temperatures, energy and flux of incident $\mathrm{H}$, and irradiated defects. Thermal desorption spectroscopy (TDS) is the main experimental technical 
tool to study the $\mathrm{H}$ retention in W. Based on the TDS peak of the desorption flux, various trapping energies and trapping sites of $\mathrm{H}$ can be obtained [40-43]. Experimental measurements [44-46] of diffusion coefficients of $\mathrm{H}$ in $\mathrm{W}$ show that $\mathrm{H}$ can be easily released once dissolved in $\mathrm{W}$ at high temperature, which means that most $\mathrm{H}$ atoms remaining in $\mathrm{W}$ are trapped and immobilized above room temperature. Thus, it is of a particular interest to determine how many $\mathrm{H}$ atoms can be trapped in $\mathrm{W}$. However, there are many types of trapping sites in the irradiated materials and those can be intrinsic/extrinsic defects, impurities and surface impurities, and so on. Considering all of them together in a single simulation seems to be impractical. In the present work, we apply the OKMC method to study the trapping behaviour of $\mathrm{H}_{\mathrm{m}} \mathrm{V}_{\mathrm{n}}$ clusters to $\mathrm{H}$ atoms by varying temperature, size of clusters, and $\mathrm{H}$ concentration. The number of trapped $\mathrm{H}$ atoms in $\mathrm{V}$ clusters is determined by balancing the trapping process and dissociation process. We find that the retention of $\mathrm{H}$ atoms in $\mathrm{W}$ is, as expected, dependent on the state of the trapping sites and temperature. Further studies are needed to explore the effects of the grain boundary, dislocation, and impurity atoms on the $\mathrm{H}$ retention in $\mathrm{W}$.

\section{Conclusions}

We have studied the clustering behaviour of hydrogen $(\mathrm{H})$ with vacancy $(\mathrm{V})$ clusters in tungsten $(\mathrm{W})$ by using Object Kinetic Monte Carlo (OKMC). The results show that the temperature and sizes of V clusters can have significant influences on the interaction of $\mathrm{H}$ atoms with $\mathrm{V}$ clusters. The maximum trapped $\mathrm{H}$ atoms in monovacancy decreases when the temperature increases, which is 8,6 , and 5 at 300 $\mathrm{K}, 600 \mathrm{~K}$, and $1000 \mathrm{~K}$, respectively, and largely different from the atomic simulation results obtained at $0 \mathrm{~K}$. The reason can be attributed to the increased emission probability of $\mathrm{H}$ atoms at high temperature. When the sizes of V clusters increase, their trapping abilities significantly drop if we assume the total amount of $\mathrm{V}$ to be the same. This is due to the binding energies of $\mathrm{H}_{\mathrm{m}} \mathrm{V}_{\mathrm{n}}$ clusters decrease gradually as the number of trapped $\mathrm{H}$ atoms increases. For the case of the given saturated $\mathrm{H}$ concentration, the average number of trapped $\mathrm{H}$ atoms is much larger than the one in the unsaturated case for identical $\mathrm{V}$ cluster sizes. This is due to the $\mathrm{V}_{\mathrm{n}}$ clusters that can trap as many $\mathrm{H}$ atoms when the $\mathrm{H}$ concentration is 
saturated. The average number of trapped $\mathrm{H}$ atoms in $\mathrm{V}$ clusters in the saturated case increases with increasing sizes of V clusters, which is in contrary to the one in the unsaturated case. To conclude, the trapping behavior of $\mathrm{V}_{\mathrm{n}}$ clusters in saturated $\mathrm{H}$ concentration is largely different from that in unsaturated conditions and is mainly determined by the sizes of vacancy clusters. Our final goal is to integrate more irradiated defects into the OKMC model, and to understand the $\mathrm{H}$ retention under irradiation. We believe that the present simulations can provide useful references for understanding the clustering of $\mathrm{H}$ and $\mathrm{V}$ in $\mathrm{W}$.

\section{Acknowledgements}

This work is supported by the National Natural Science Foundation of China (Grant No. 51720105006, 11675009), and the Science Challenge Project (Grant No. JCKY 2016212A502).

\section{References}

[1] T. Hirai, S. Panayotis, V. Barabash, C. Amzallag, F. Escourbiac, and A. Durocher, Use of tungsten material for the ITER divertor, Nucl. Mater. Energy 9 (2017) 616-622.

[2] R. a. Causet and T. J. Venhaus, The Use of Tungsten in Fusion Reactors: A Review of the Hydrogen Retention and Migration Properties, Phys. Scr. T94 (2001) 9.

[3] J. B. Condon and T. Schober, Hydrogen bubbles in metals, J. Nucl. Mater. 207 (1993) 1-24.

[4] O. V. Ogorodnikova, J. Roth, and M. Mayer, Ion-driven deuterium retention in tungsten, J. Appl. Phys. 103 (2008).

[5] O. V Ogorodnikova, B. Tyburska, V. K. Alimov, and K. Ertl, The influence of radiation damage on the plasma-induced deuterium retention in self-implanted tungsten, J. Nucl. Mater. 415 (2011) S661-S666.

[6] S. Qin, S. Jin, L. Sun, H. Zhou, Y. Zhang, and G. Lu, Hydrogen assisted vacancy formation in tungsten : A first-principles investigation, J. Nucl. Mater. 465 (2015) 135-141.

[7] Y. L. Liu, Y. Zhang, H. B. Zhou, G. H. Lu, F. Liu, and G. N. Luo, Vacancy trapping mechanism for hydrogen bubble formation in metal, Phys. Rev. B - Condens. Matter Mater. Phys. 79 (2009) 1-4.

[8] L. Sun, S. Jin, X. C. Li, Y. Zhang, and G. H. Lu, Hydrogen behaviors in molybdenum and tungsten and a generic vacancy trapping mechanism for $\mathrm{H}$ bubble formation, J. Nucl. Mater. 434 (2013) 395-401. 
[9] G. Valles, M. Panizo-Laiz, C. González, I. Martin-Bragado, R. González-Arrabal, N. Gordillo, R. Iglesias, C. L. Guerrero, J. M. Perlado, and A. Rivera, Influence of grain boundaries on the radiation-induced defects and hydrogen in nanostructured and coarse-grained tungsten, Acta Mater. 122 (2017) 277-286.

[10] L.-F. Wang, X. Shu, G.-H. Lu, and F. Gao, Embedded-atom method potential for modeling hydrogen and hydrogen-defect interaction in tungsten, J. Phys. Condens. Matter (2017).

[11] L. Wang, X. Shu, G. Lu, and F. Gao, Energetics and structures of hydrogen-vacancy clusters in tungsten based on genetic algorithm6, Sci. China Physics, Mech. Astron. 61 (2018) 107022.

[12] Y. L. Liu, H. B. Zhou, and Y. Zhang, Investigating behaviors of H in a W single crystal by first-principles: From solubility to interaction with vacancy, J. Alloys Compd. 509 (2011) 8277-8282.

[13] X. Yang and A. Hassanein, Kinetic Monte Carlo simulation of hydrogen diffusion on tungsten reconstructed (0 0 1) surface, Fusion Eng. Des. 89 (2014) 2545-2549.

[14] X. Yang and W. O. Oyeniyi, Kinetic Monte Carlo simulation of hydrogen diffusion in tungsten, Fusion Eng. Des. 114 (2017) 113-117.

[15] T. Oda, D. Zhu, and Y. Watanabe, Kinetic Monte Carlo simulation on influence of vacancy on hydrogen diffusivity in tungsten, J. Nucl. Mater. 467 (2015) 439-447.

[16] N. Castin, A. Bakaev, G. Bonny, A. E. Sand, L. Malerba, and D. Terentyev, On the onset of void swelling in pure tungsten under neutron irradiation: An object kinetic Monte Carlo approach, J. Nucl. Mater. 493 (2017) 280-293.

[17] N. Castin, G. Bonny, A. Bakaev, C. J. Ortiz, A. E. Sand, and D. Terentyev, Object kinetic Monte Carlo model for neutron and ion irradiation in tungsten : Impact of transmutation and carbon impurities, J. Nucl. Mater. 500 (2018) 15-25.

[18] C. Meng, J. Hao, K. Xu, L. Wang, X. Shu, S. Jin, and G. Lu, Kinetic Monte Carlo codedevelopment and application on the formation of hydrogen-vacancy clusters in tungsten, Sci. China Physics, Mech. Astron. 62 (2019) 017111.

[19] C. S. Becquart, C. Domain, U. Sarkar, A. Debacker, and M. Hou, Microstructural evolution of irradiated tungsten: Ab initio parameterisation of an OKMC model, J. Nucl. Mater. 403 (2010) $75-88$.

[20] G. H. Vineyard, Frequency factors and isotope effects in solid state rate processes, J. Phys. Chem. Solids 3 (1957) 121-127.

[21] M. Rao, M. H. Kalos, J. L. Lebowitz, and J. Marro, Time evolution of a quenched binary alloy. III. Computer simulation of a two-dimensional model system, Phys. Rev. B 13 (1976).

[22] C. S. Becquart and C. Domain, Ab initio calculations about intrinsic point defects and $\mathrm{He}$ in W, 
Nucl. Instruments Methods Phys. Res. Sect. B Beam Interact. with Mater. Atoms 255 (2007) $23-26$.

[23] K. Heinola, F. Djurabekova, and T. Ahlgren, On the stability and mobility of di-vacancies in tungsten, Nucl. Fusion 58 (2018).

[24] D. Kato, H. Iwakiri, and K. Morishita, Formation of vacancy clusters in tungsten crystals under hydrogen-rich condition, J. Nucl. Mater. 417 (2011) 1115-1118.

[25] S. Jin, Y. L. Liu, H. B. Zhou, Y. Zhang, and G. H. Lu, First-principles investigation on the effect of carbon on hydrogen trapping in tungsten, J. Nucl. Mater. 415 (2011) S709-S712.

[26] Y. L. Liu, Y. Zhang, G. N. Luo, and G. H. Lu, Structure, stability and diffusion of hydrogen in tungsten: A first-principles study, J. Nucl. Mater. 390-391 (2009) 1032-1034.

[27] R. Frauenfelder, Solution and Diffusion of Hydrogen in Tungsten, J. Vac. Sci. Technol. 388 (1969) 3.

[28] Y.-N. Liu, T. Wu, Y. Yu, X.-C. Li, X. Shu, and G.-H. Lu, Hydrogen diffusion in tungsten: A molecular dynamics study, J. Nucl. Mater. 455 (2014) 676-680.

[29] D. F. Johnson and E. A. Carter, Hydrogen in tungsten: Absorption, diffusion, vacancy trapping, and decohesion, J. Mater. Res. 25 (2010) 315-327.

[30] T. Hirai, S. Carpentier-Chouchana, F. Escourbiac, S. Panayotis, A. Durocher, L. Ferrand, M. Garcia-Martinez, J. P. Gunn, V. Komarov, M. Merola, R. A. Pitts, and G. De Temmerman, Design optimization of the ITER tungsten divertor vertical targets, Fusion Eng. Des. 127 (2018) 66-72.

[31] J. H. You, E. Visca, T. Barrett, B. Böswirth, F. Crescenzi, F. Domptail, M. Fursdon, F. Gallay, B. E. Ghidersa, H. Greuner, M. Li, A. V. Müller, J. Reiser, M. Richou, S. Roccella, and C. Vorpahl, European divertor target concepts for DEMO: Design rationales and high heat flux performance, Nucl. Mater. Energy 16 (2018) 1-11.

[32] F. Maviglia, G. Federici, G. Strohmayer, R. Wenninger, C. Bachmann, R. Albanese, R. Ambrosino, M. Li, V. P. Loschiavo, J. H. You, and L. Zani, Limitations of transient power loads on DEMO and analysis of mitigation techniques, Fusion Eng. Des. 109-111 (2016) $1067-1071$.

[33] D. Kato, H. Iwakiri, and K. Morishita, First-principle Study on Binding Energy of VacancyHydrogen Cluster in Tungsten First-principle Study on Binding Energy of Vacancy-Hydrogen Cluster in Tungsten, J. Plasma Fusion Res. (2014).

[34] N. Fernandez, Y. Ferro, and D. Kato, Hydrogen diffusion and vacancies formation in tungsten: Density Functional Theory calculations and statistical models, Acta Mater. 94 (2015) 307-318.

[35] X. Hu, T. Koyanagi, M. Fukuda, Y. Katoh, L. L. Snead, and B. D. Wirth, Defect evolution in 
single crystalline tungsten following low temperature and low dose neutron irradiation, J. Nucl. Mater. 470 (2016) 278-289.

[36] B. Fu, M. Qiu, J. Cui, M. Li, and Q. Hou, The trapping and dissociation process of hydrogen in tungsten vacancy: A molecular dynamics study, J. Nucl. Mater. 508 (2018) 278-285.

[37] H. Eleveld and A. van Veen, Void growth and thermal desorption of deuterium from voids in tungsten, J. Nucl. Mater. 212-215 (1994) 1421-1425.

[38] F. Ferroni, X. Yi, K. Arakawa, S. P. Fitzgerald, P. D. Edmondson, and S. G. Roberts, High temperature annealing of ion irradiated tungsten, Acta Mater. 90 (2015) 380-393.

[39] T. Tanabe, Review of hydrogen retention in tungsten, Phys. Scr. T159 (2014).

[40] V. K. Alimov, B. Tyburska-Püschel, S. Lindig, Y. Hatano, M. Balden, J. Roth, K. Isobe, M. Matsuyama, and T. Yamanishi, Temperature dependence of surface morphology and deuterium retention in polycrystalline ITER-grade tungsten exposed to low-energy, high-flux D plasma, J. Nucl. Mater. 420 (2012) 519-524.

[41] H. T. Lee, A. A. Haasz, J. W. Davis, R. G. Macaulay-Newcombe, D. G. Whyte, and G. M. Wright, Hydrogen and helium trapping in tungsten under simultaneous irradiations, J. Nucl. Mater. 363-365 (2007) 898-903.

[42] W. R. Wampler, D. L. Rudakov, J. G. Watkins, and C. J. Lasnier, The influence of displacement damage on deuterium retention in tungsten exposed to divertor plasma in DIII-D, J. Nucl. Mater. 415 (2011).

[43] M. Fukumoto, H. Kashiwagi, Y. Ohtsuka, Y. Ueda, M. Taniguchi, T. Inoue, K. Sakamoto, J. Yagyu, T. Arai, I. Takagi, and T. Kawamura, Deuterium trapping in tungsten damaged by high-energy hydrogen ion irradiation, J. Nucl. Mater. 390-391 (2009) 572-575.

[44] R. Frauenfelder, Permeation of Hydrogen through Tungsten and Molybdenum, J. Chem. Phys. 48 (1968) 3955-3965.

[45] T. Ikeda, T. Otsuka, and T. Tanabe, Application of tritium tracer technique to determination of hydrogen diffusion coefficients and permeation rate near room temperature for tungsten, Fusion Sci. Technol. 60 (2011) 1463-1466.

[46] T. Otsuka, M. Shimada, R. Kolasinski, P. Calderoni, J. P. Sharpe, Y. Ueda, Y. Hatano, and T. Tanabe, Application of tritium imaging plate technique to examine tritium behaviors on the surface and in the bulk of plasma-exposed materials, J. Nucl. Mater. 415 (2011) S769-S772. 